\title{
Healthcare Levels Cooperation, Action in Local Health System to Better Coordinate the Delivery of Healthcare
}

\author{
Alberto PARADA, MD \\ Département de Médecine Générale, Université de Liège, Belgique
}

\begin{abstract}
The healthcare system's approach considers the complexity and interactions between organized elements. In continuous processing, healthcare systems are affected by their constituent elements, themselves modified with each system change. To secure and optimize the system of care, collaboration between levels is necessary. Almost no documented experience to better coordination of levels of care in the Belgian system is available. To improve the quality of care, the system needs collaborative coordination between stakeholders. Good coordination improves the quality of patient care, it makes quality more efficient and optimal care. This coordination between care lines must be collaborative. Interactional communication is the founding element of inter-professional collaboration. A good self-esteem improves the relationship between actors in the health system and supports the initiatives and adaptability. It contributes therefore to an increase of the quality of care. The interactional Local Health System promotes cooperation in the relevant health network. Consultation and coordination between the actors involved and motivated bring care quality and operational solutions. This dynamic modality of exchanges appears fruitful as participants continue to meet and coordinate care, even after the official end of the action-research. The climate became conducive to solving real problems through the skills developed in the LHS.
\end{abstract}

Key words: Local Health System, healthcare coordination, health communication skills, inter-professional collaboration, care quality, cooperation, interactional communication.

\section{Introduction}

The health care system in Belgium by its mode of operation, its lack of timing does not encourage the clear division of labor, it does not encourage collaboration but rather gives rise to a competition between different care actors and in particular between the first and second line cares.

The GP by its function of synthesis and integration is required to coordinate with many specialists.

Continuity of patient care [1], essential function of our health care system is defined by;

- The information, that is transmitted from one caregiver to another on events related to the disease and the patient, to be able to provide care.

- The therapeutic relationship doctor-patient in its singularity that reflects the transitions taking place

Corresponding author: Alberto PARADA, M.D., research fields: family medicine, health communication, medical relationship, primary care and medical empowerment. between the different care episodes.

- The organizational approach capable of ensuring the coordination of care. This aspect refers to the complementarity of services so that they are neither missing nor repeated, nor out of synch.

Efforts to improve the quality of care must address both the fairness of the evaluation of medical performance, equitable distribution of resources and reduce disparities in care for vulnerable patients [2].

We must reflect on the modalities of efficient care and adapt to the target audience. The first level of care supports the majority (over 90\%) of the health problems of a population $[3,4]$.

Deficits in communication and information transfer between the first and second care line treatments are common and can affect the quality of patient care [5].

The care provided and methods of medical practice are not identical whether the patient is hospitalized or not $[1,6]$. 
There are no formal mechanisms to coordinate actions between levels of care.

The system suffers from lack of coordination between at least first and second care levels. Communication patterns between GPs and hospital doctors are lacking.

To secure and optimize the system of care, collaboration between levels is necessary but challenging.

Therefore, the quality of care is compromised.

\section{Existing Systems}

Almost no documented experience of better coordination of care's levels in the Belgian health system is available.

Good coordination improves the quality of patient care, it makes quality more efficient and the care optimal. This coordination between care lines must be collaborative.

Criteria of good collaboration, seems to be cooperation;

- Planned,

- Integrated into the daily practice of each other,

- Adapted to each patient (according to the criteria of each physician), and

- Beyond the willingness of each actor.

Certainly it exists organizing authorities initiatives; care coordination, local multidisciplinary networks.

These initiatives have the merit of existing and place the family doctor or GP as the first key player in supporting patients early but need a formal stakeholder.

The success of these initiatives is variable and more or less happy, the lessons to withdraw their changes are needed to assess.

An essential and indispensable part of the collaboration is precisely this interaction between care line, this essential element is straightforward and fundamental.

The dialogue between stakeholders is the substance of this communication [7].
There is a qualitative difference between relational collaboration and organizational coordination.

Relational Collaboration creates an interaction and communications between the actors.

Relational coordination $[8,9]$ is collaborative if it meets the four dimensions of communication; frequent, timely, accurate (and accurately), aimed at solving problems and three dimensions of relations; knowledge sharing, common goals and mutual respect.

The health systems approach considers the complexity and interactions between organized elements of larger systems (Fig. 1). The latter, in continuous processing, are affected by each of their constituent elements, themselves modified with each system change (Fig. 2).

Different types of interactions between the actors of a system coexist. According to the typology of these interactions, various aspects will be highlighted or otherwise neglected (quality, relationship, value types ...).

Interactional communication is the founding element of inter-professional collaboration.

Empathic dimension of the patient-provider relationship is fundamental to develop the individual skills of patients, but it also benefits each protagonist of this relationship at the level of inter- and intra-personal processes.

At the provider level, a good self-esteem improves the relationship with the patient (empathy, trust ...) - as well as other actors in the health system and supports the initiatives and adaptability. It therefore contributes to an increase of the quality of care.

According to the literature review conducted by (D'Amour et al., 2005), interprofessional collaboration has a fourfold impact. Several authors have identified the potential impacts of collaborative practice in health [10]. These effects can be observed in terms of clinical outcomes but also in terms of quality of service and more specifically in terms of accessibility 
and continuity of care. The satisfaction of professionals in terms of appreciation of work and well-being may also be affected. Health organizations also benefit from interprofessional collaboration since health professionals work more efficiently due to reduced duplication in the delivery of services and greater latitude for creativity. The impact on the general health system results in terms of cost and their ability to respond.

The experience of SYLOS [11] (Système Local de Santé $=$ Local Health System) is several years old and is still active.

It proposes to dialogue physicians (general practitioners and specialists), other caregivers “involved" and hospital officials

- at monthly meetings,

- discussing concrete and course common case patients (these discussions are decontextualized and ensuring guaranteeing anonymity, they focus on the problem, the methods and means used, not on the patient person)

- as part of a reflection and using an analysis grid.

It examines the different actors, sets, critical situations and seek consensus solutions.

The dynamics and modalities of the LHS (MalmedySylos) allow us to identify the interrelationships and thus use in real time, the process of interprofessional collaboration.

The concrete results are tangible.

Study methodology and the proposed solutions are in line with the recommendations of good practice and evidence based medicine, they are adapted to the possibilities, qualities and local resources available.

Associations of General Practitioners, through their authorized representatives, are participatory and integrated in hospital decisions, which make probably this collaboration more efficient.

The identification of needs produces the appropriate training, which in turn allows the productive evaluation (and often additional, in team- consensual resolution).

\section{Results}

The SYLOS can be considered as an official place with formalized interchanges setting the patient in the care process center.

What about patient support and communication?

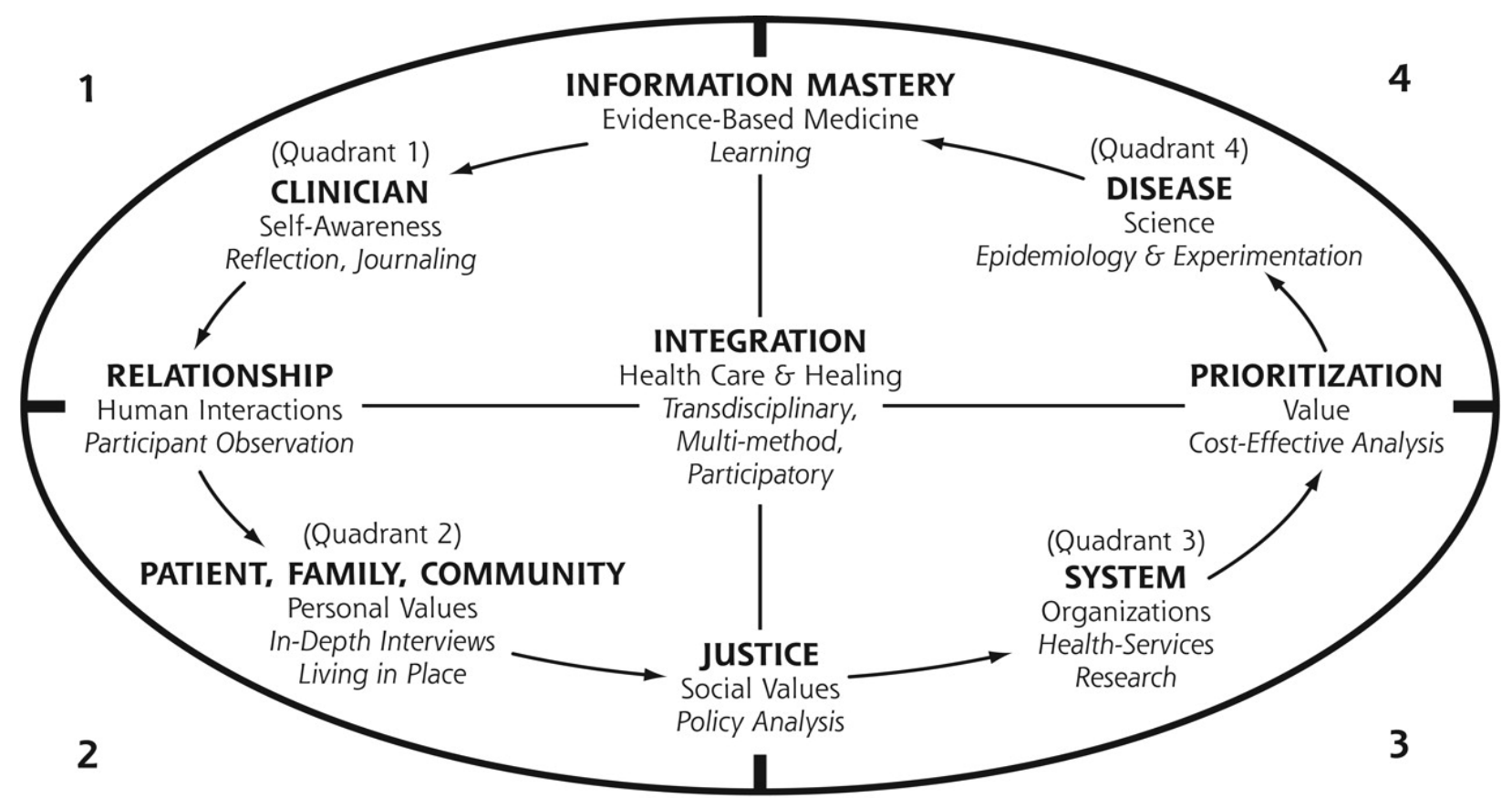

For each item, bold capitalized words on the first line signify "FOCUS OF KNOWLEDGE," normal text on the second line signifies the "Task of Understanding," and italicized words on the third line signify the "Mode of Inquiry."

Fig. 1 Comprehensive, functional and integrated health care system. 
The SYLOS is the ideal crucible (Fig. 2, mesosystem) for the development of conditions of collaboration from a particular context and determined by local actors themselves.

Conditions for success in SYLOS could be:

- Active participation of professionals involved

- Plural interests

- In (small) determinated areas

- Staff and confident links among participants

When is communication INTERACTIVE [12] between GP and specialist doctors?

The conditions for a good relationship and a high quality communication are:

\section{Mutual respect}

2. Recognize the competence of each

3. Division of tasks and functions together, through dialogue, based on local needs

4. In practical and operationally

5. Dare to entrust the patient to another

6. In collaboration with the patient himself, his entourage and other health care stakeholders.

In Belgium, professional networks exist and act outside (interfering and changing the condition) system. The SYLOS works from the inside in the system, it is already integrated and accepted by all the elements, it is itself a component of the system (network).

All participants have a role and are protagonist in the local health system. It is present and active in everyday reality, in practical problem, in existing challenge.

The values to reinforce, the principles to improve the self-esteem of participants (respect, recognition, autonomy, competence...) are pragmatic and realistic to all levels of the health system.

The Local Health System (SYLOS) is a cybernetic tending approach to healthcare systems.

Contribution of SYLOS is discussion interface to reach (treatment's) consensus about issues involving the first and second care-lines.

Which coordination for SYLOS?

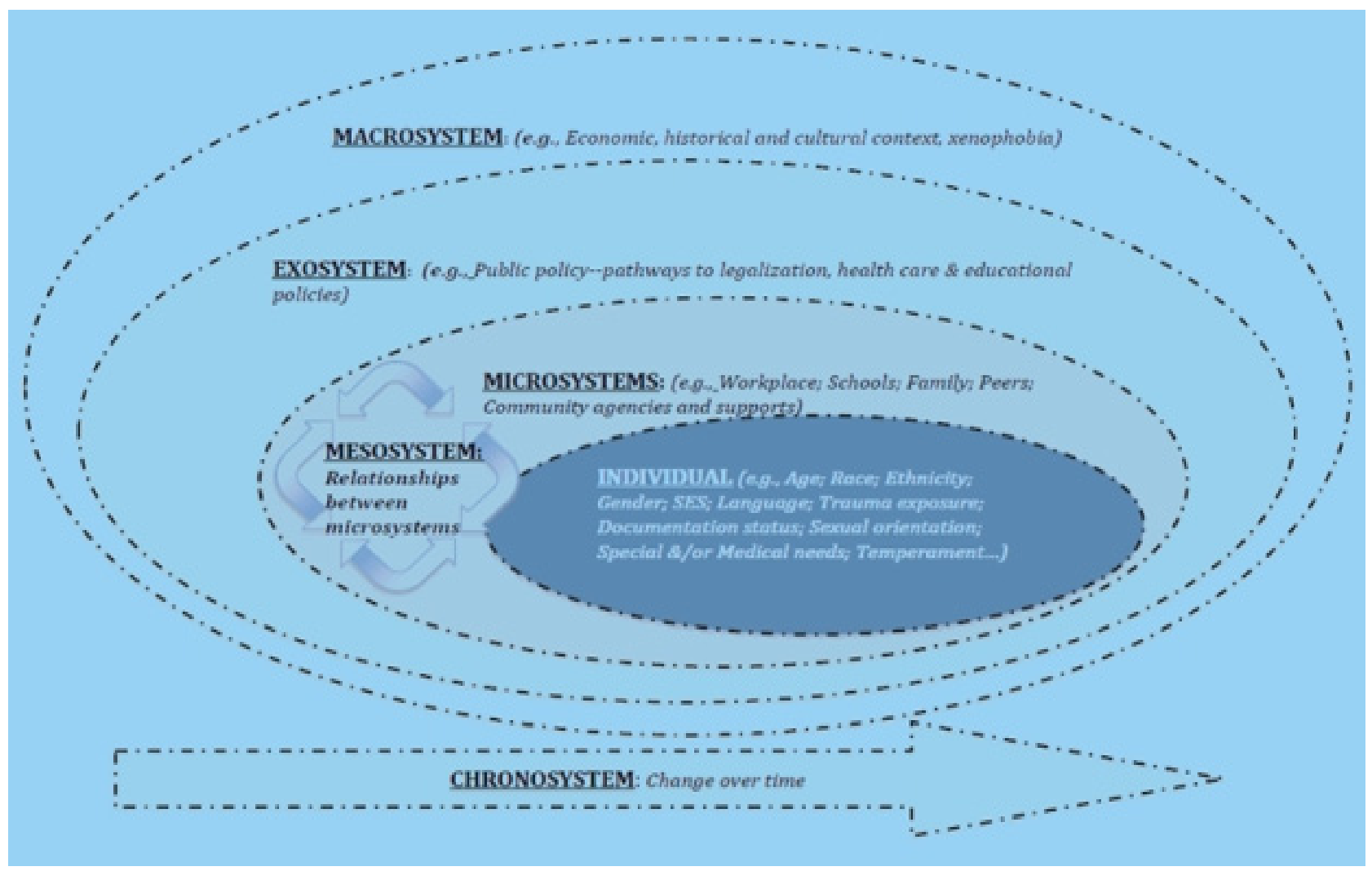

Fig. 2 LHS cybernetics. 


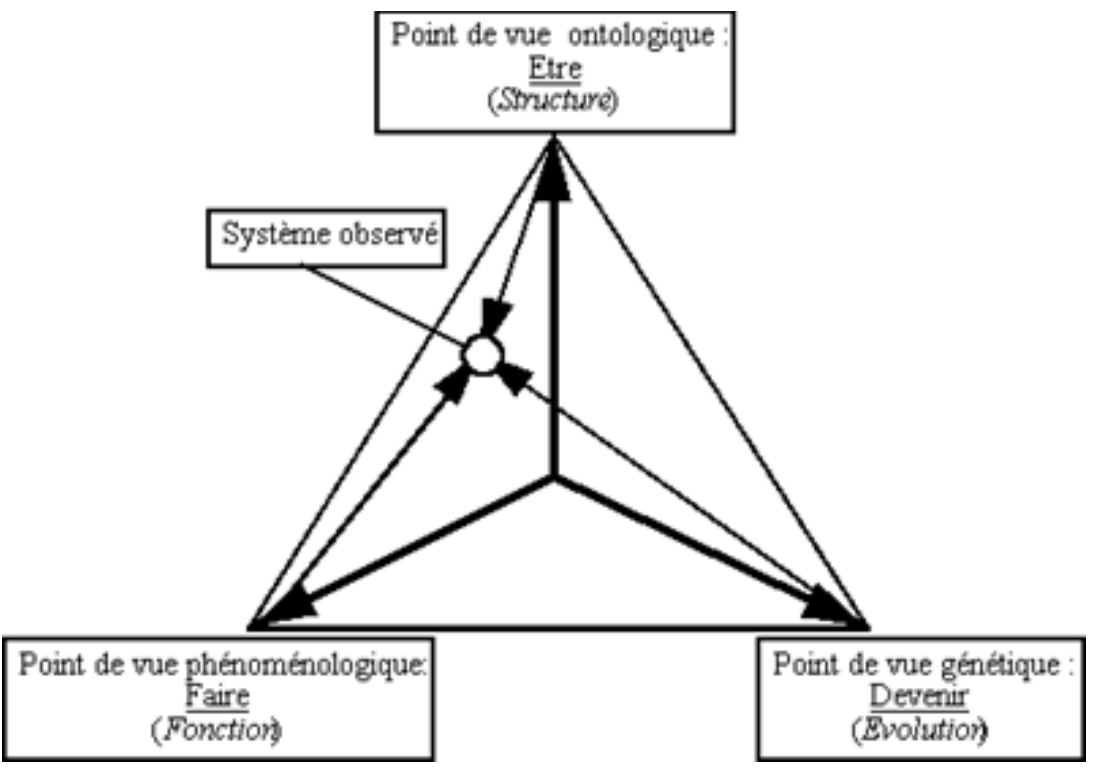

Fig. 3 Customized support and external point of view on SyLos.

The SYLOS has no formal responsibility or official identity.

The help of a group spearhead (coordinator) plays a leading role in improving coordination.

He's not caring "involved", he acts within the system, as constituting part's full system, it is probably an invested actor of change.

$\mathrm{He}$ raises the conviction and the commitment of practitioners (Sylos participants who have learned to know in order to highlight the problems and try to bring together constructive solutions).

The interactional Sylos promotes cooperation in the relevant health network.

Consultation and coordination between the actors involved and motivated to bring care-focused and operational solutions (which are then developed and operationalized...) are the essential and main steps.

Secondary outcomes of this action-research are important.

Participants continue to meet and coordinate care, beyond the official end of the action-research.

The climate became conducive to solving real problems through the skills developed in the LHS.

The relational cooperation dynamics improves with the practical experience among stakeholders in Malmedy's LHS.

\section{References}

[1] Reid, R., Haggerty, J., and McKendry, R. 2002. Dissiper la confusion: concepts et mesures de la continuité des soins. Ottawa: Fondation canadienne de la recherche sur les services de santé; mars.

[2] Starfield, B., Leiyu, S., and James M. 2005. "Contribution of Primary Care to Health Systems and Health.” The Milbank Quarterly 83 (3): 457-502.

[3] White, K. L., Williams, T. F., and Greenberg, B. G. 1961. "The Ecology of Medical Care." N. Engl. J. Med. 265: 885-92.

[4] White, K. 1997. "The Ecology of Medical Care: Origins and Implications for Population-based Healthcare Research." HSR Health Serv. Res. 32: 11-21.

[5] Starfield, B. 1994. "Is Primary Care Essential?" Lancet 344: 1129-33.

[6] Kripalani, S., LeFevre, F., Phillips, C. O., Williams, M. V., Basaviah, P., and Baker, D. W. 2007. "Deficits in Communication and Information Transfer between Hospital-Based and Primary Care Physicians: Implications for Patient Safety and Continuity of Care." JAMA. 297 (8): 831-41. doi:10.1001/jama.297.8.831.

[7] Michael E. Porter 2010. "What Is Value in Health Care?" N. Engl. J. Med. 363: 2477-81.

[8] Longest, B. B., and Young, G. J. 1999. "Coordination and communication" in: Shortell M, Kaluzny AD, eds. Health Care Management, Organizations Design and Behavior, 4th ed. Albany, NY: DelmarThomson Learning: 21043.

[9] Phanuel Dominique. Confiance dans les soins et soin de la confiance: la réponse relationnelle. In: Politiques et management public, vol. 20, n 4, 2002. Numéro spécial: « 


\section{Better Coordinate the Delivery of Healthcare}

L'évaluation de l'action publique: pour quand?». pp. 115-32.

[10] High Performance Healthcare: Using the Power of Relationships to Achieve Quality, Efficiency and Resilience, by Jody Hoffer Gittell, McGraw-Hill Education; 1 edition (July 13, 2009) 335 pages, ISBN-10: 0071621768 .

[11] Michele Kosremelli Asmar, Frederic Wacheux. Facteurs influencant la collaboration interprofessionnelle: cas d'un hopital universitaire. Universite Saint-Joseph. Conference
Internationale en Management, Feb 2007, Beyrouth, Lebanon. pp. 57-75.

[12] Unger, J. P. 2004. «Les systèmes locaux de santé (SYLOS), une démarche de recherche-action pour l'amélioration de la coordination entre hôpital et médecins généralistes », Santé conjuguée n 30, pp. 29-32.

[13] Foy, R., Hempel, S., and Rubenstein, L., et al. 2010. "Meta-analysis: Effect of Interactive Communication between Collaborating Primary Care Physicians and Specialists." Ann. Intern. Med. 152: 247-58. 